\title{
A METHOD TO OPTIMIZE SCHEDULING IN SMALL BATCH MANUFACTURING
}

\author{
Adrián Guillermo Lucero ${ }^{1}$, Abelardo Alves de Queiroz ${ }^{2}$ \\ ${ }^{1}$ Dep. of Mechanical Eng., UFSC, CEP 88040-900. CP N 476, Florianópolis, SC, Brazil \\ aglucero@grucon.ufsc.br \\ ${ }^{2}$ Dep. of Mechanical Eng, UFSC, CEP 88040-900. CP N 476, Florianópolis, SC, Brazil. \\ abelardo@emc.ufsc.br
}

\begin{abstract}
This paper reports on research into the development of a procedure that improves the way to arrange job shop schedules. The principal components of the method are a) Remove early restrictions to the schedule process; and b) Decide the manufacturing routes as late as possible. A complete method description is presented, including the conceptual model and the method development with the application of Bellman's dynamic programming technique. The tool has been programmed and made available in software for integration into production planning and scheduling systems such as MRP and ERP.
\end{abstract}

\section{INTRODUCTION}

The manufacturing process underwent dramatic changes in concepts and methods in the early $1980^{\prime} \mathrm{s}$, and worldwide markets along with the objectives of manufacturing systems demanded change. The new manufacturing process is a chain of activities directed toward meeting a set of objectives defined by management. These objectives such as non-engineering functions of the organization including sales, marketing and finance, together with engineering functions such as product development, part production, assembly of products, customer production design, etc, changed to give more emphasis on competitiveness.

Modern production no longer can rely on general methods and procedures. Focused transformation and management processes lead to progressively more specialized technology in order to achieve better performance. In the past management methods were applied across the board for the whole manufacturing arena, but nowadays they are developed for different size plants, types of industry and types of production. The focused approach leads to more specialized and optimized solutions. The trend for the future certainly will be a different solution for each company.

Small-batch manufacturing is a very particular type of production which has been well described by Rantakyro (2000) as follows: "Production is very difficult to plan, because there are many customers and a lot of different products are fabricated. The companies bid on all jobs, and products are produced in very small batches, 
sometimes a lot size of one. Generally they fabricate parts for the manufacturing industry or provide services for large companies like mines, steel, mills, paper mills, and the wood industry. There have been changes in the relationship with bigger corporations during the last decade. The manufacturing industry no longer has longterm contracts, and they want parts delivered just-in-time, in small batches, or only a couple of weeks' or days' production.".

This type of production in which a great variety of products are manufactured in a specific short time period and the material flow for producing each of these products is not similar and often complicated, can be characterized as follows (HITOMI, 1979):

- Variety of product items - With diverse production volumes and due dates;

- Variety of manufacturing processes - Frequently complicated;

- Complexity of productive capacity - Because of the dynamic nature of demand;

- Uncertainty of outside conditions - There are frequent changes in product specification, due dates and volumes;

- Difficulty of production planning and scheduling - Because of topics described above;

- Dynamic implementation conditions and control of production - Due to the uncertainty of outside conditions.

Examples of this type of manufacturing are the aeronautical industry and all its supply chain, the naval chain sector and part of the measurement instruments industry. All shop floors have process layouts and the principal planning characteristic that the product must be scheduled in order to fulfill the customer delivery promise, because the customers are as interested in delivery time as product price.

\section{THE SCHEDULING METHOD}

The method has a general philosophy: the decisions on manufacturing routes must be taken at the last possible moment in order to avoid other early restrictions, which may compromise both delivery time and cost.

Commonly the process planners choose the manufacturing routes based on their experience. A decision is taken at the beginning, so process planners details and schedulers view routes as a restriction.

The present model analyzes all alternative machines for each operation, develops process plans, defines the criterion for the optimization (time, cost or profit) and defines the best route for each manufacturing task. After taking into considering resource restrictions it defines the best schedule. A schematic presentation of the method model follows (Fig.1): 


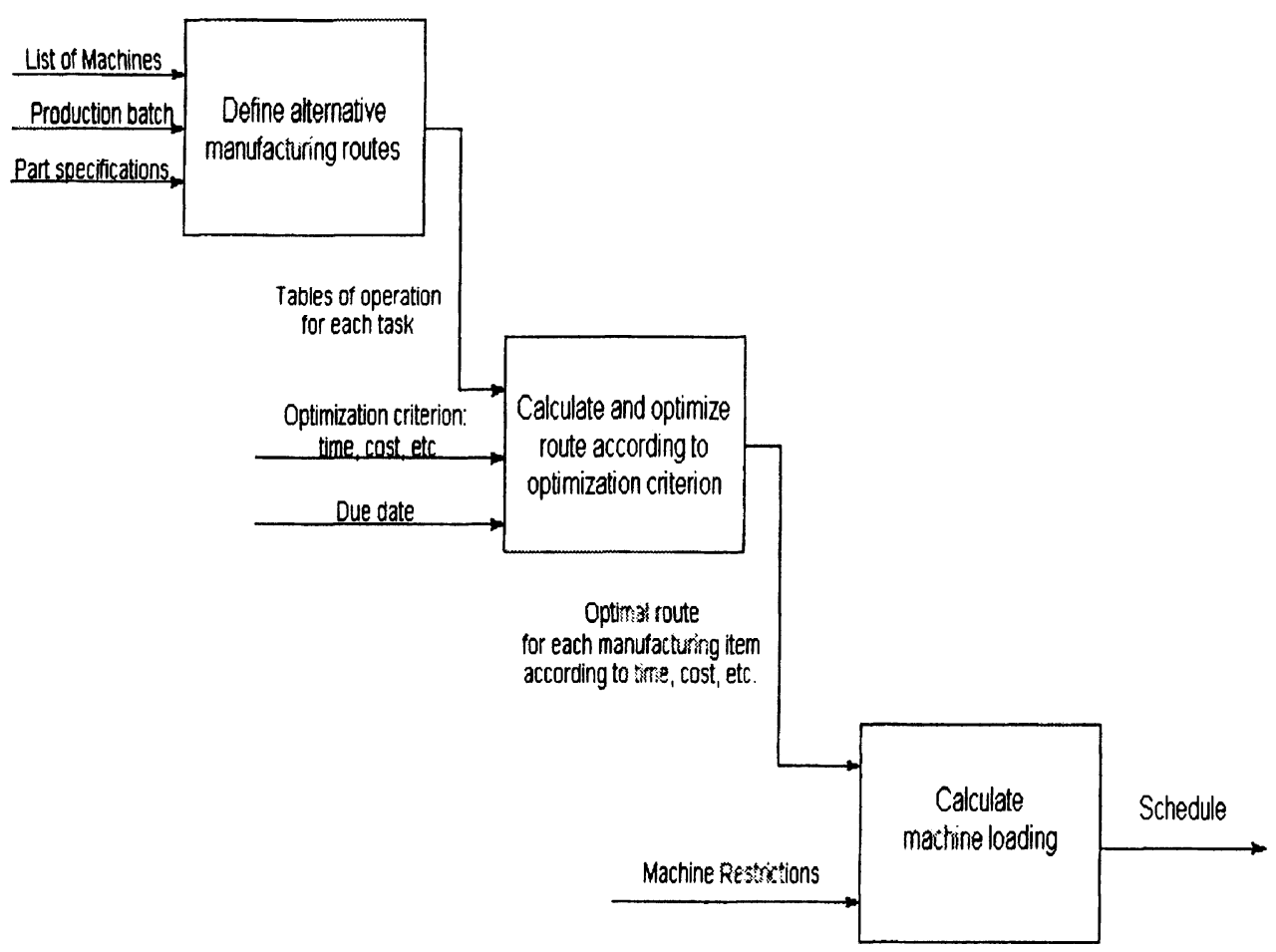

Figure 1 - Conceptual Scheduling Model

So, the steps necessary to schedule the manufacturing process according to the method are:

i. STEP 1: Define alternative manufacturing routes;

ii. STEP 2: Calculate and optimize route according to criterion;

iii. STEP 3: Calculate machine loading taking alternative machines into consideration;

\subsection{STEP 1: Define Alternative Manufacturing Routes}

The method begins by collecting specifications of the part design; including the production batch and the list of machines that comprise the shop. The process planners supply the necessary information for the process plan after dividing the job into operations. In this step all the alternative machines for each operation are considered in order to avoid early decisions that cause unnecessary constraints to planning the workflow.

The data collection is presented in three matrices that give information about Operation Time $\mathrm{T}(\mathrm{o}, \mathrm{m})$, Setup Time $\mathrm{S}(\mathrm{o}, \mathrm{m})$ and Transfer Time $\mathrm{R}(\mathrm{i}, \mathrm{j})$. The Operation Time matrix is arranged in lines that represent operation numbers, which establish the precedent relation among operations; and columns of machines. The matrix is filled with operation times for single items $T_{\text {om }}$ defined in the process planning. When a time/machine combination for the operation does not make sense for technological reasons a number 99 is placed in the position.

The second matrix expresses the Setup Time $S(0, m)$ and each position on the matrix is constructed in the same fashion as the Operation Time table. 
The third matrix expresses the Transfer Time $R(i, j)$ between each of the two machines.

\subsection{STEP 2: Calculate and Optimize Route According to Criterion}

The calculation of optimal manufacturing route for each task uses, as input, the data inserted in the matrices from STEP 1 and the optimization criterion chosen following strategic policies.

The Operation Time matrix and the Setup Time matrix for a previously defined batch are combined in a single table (Table 1), because both are related to the operation itself. The Transfer Time matrix (Table 2) and the optimal criterion complete the data needs for the calculation of optimal manufacturing routes in this step.

Table 1 - Times of $\mathrm{T}(\mathrm{o}, \mathrm{m})$ and $\mathrm{S}(\mathrm{o}, \mathrm{m})$ Combined for Single Item Production

\begin{tabular}{c|c|c|c|c|c|c}
\hline \multicolumn{7}{c}{ T(o,m) + S(o,m)-Times } \\
\hline Operation & Machine 1 & Machine2 & Machine3 & Machine4 & Machine5 & Machine6 \\
\hline 1 & 0.8 & 0.67 & 1.28 & 99 & 1.62 & 1.18 \\
\hline 2 & 0.52 & 0.48 & 0.88 & 99 & 1.22 & 0.59 \\
\hline 3 & 0.61 & 0.81 & 0.97 & 99 & 0.46 & 99 \\
\hline 4 & 2.58 & 2.04 & 1.99 & 99 & 99 & 2.14 \\
\hline 5 & 0.55 & 0.8 & 0.99 & 99 & 1.32 & 0.74 \\
\hline 6 & 4.38 & 4.51 & 4.82 & 99 & 99 & 4.41 \\
\hline 7 & 0.48 & 0.49 & 0.69 & 0.69 & 1.03 & 0.1 \\
\hline 8 & 0.37 & 0.38 & 0.88 & 0.88 & 1.22 & 0.47 \\
\hline
\end{tabular}

Table 2 - Transfer Time Table R(i,j)

\begin{tabular}{c|c|c|c|c|c|c}
\hline Mach/Mach & Machine1 & Machine2 & Machine3 & Machine4 & Machine5 & Machine6 \\
\hline Mach.1 & 0 & 3.0 & 2.6 & 4.7 & 3.2 & 2.9 \\
\hline Mach.2 & 3.0 & 0 & 2.4 & 3.1 & 2.8 & 4.0 \\
\hline Mach.3 & 2.6 & 2.4 & 0 & 2.5 & 3.4 & 2.2 \\
\hline Mach.4 & 4.7 & 3.1 & 2.5 & 0 & 4.1 & 5 \\
\hline Mach.5 & 3.2 & 2.8 & 3.4 & 4.1 & 0 & 2.9 \\
\hline Mach.6 & 2.9 & 4.0 & 2.2 & 5 & 2.9 & 0 \\
\hline
\end{tabular}

The method uses the Dynamic Programming technique (Bellman, 1957) and the procedure called the Halevi Matrix (Halevi, 1993 and 1999), an adaptation of Dynamic Programming for this kind of problem.

The optimal manufacturing route is arrived at through the calculation of the minimum Cumulative Time table or $\mathrm{Z}$ table. Eq. 1 gives the general equation for the elements of $\mathrm{Z}$ :

$$
Z_{i, j}=\min _{k=1 \rightarrow m}\left\lfloor T_{i, j}+Z_{i+1, k}+R_{j, k}\right\rfloor \quad \begin{aligned}
\text { where } \mathrm{i} & =o-1 \text { to } 1 \quad \text { Eq. (1) } \\
\mathrm{j}=1 \text { to } m &
\end{aligned}
$$

and $\quad o$ : operations number

$m$ : machines number 
With the initial condition

$$
Z_{o, j}=T_{o, j}
$$

where $\mathrm{j}=1$ to $m$

Eq. (2)

The numeric example shows the calculation of the two tables with data from Tables 1 and 2 . The analysis of the two tables leads to the minimum cumulative lead-time and the manufacturing route necessary to obtain this value as shown in Tables 3 and 4.

Table 3 - Table of Minimum Cumulative Time Z(i,j)

\begin{tabular}{c|c|c|c|c|c|c}
\hline Operations & Machine1 & Machine2 & Machine3 & Machine4 & Machine5 & Machine6 \\
\hline 1 & 9.74 & 9.57 & 10.27 & 108.02 & 10.63 & 10.19 \\
\hline 2 & 8.94 & 8.9 & 9.32 & 107.47 & 9.52 & 9.012 \\
\hline 3 & 8.42 & 8.58 & 8.68 & 106.81 & 8.30 & 106.8 \\
\hline 4 & 8.19 & 7.77 & 7.71 & 104.80 & 104.74 & 7.86 \\
\hline 5 & 5.61 & 5.94 & 6.06 & 104.18 & 6.41 & 5.72 \\
\hline 6 & 5.06 & 5.24 & 5.48 & 99.77 & 99.68 & 4.98 \\
\hline 7 & 0.85 & 0.87 & 1.16 & 1.194 & 1.52 & 0.57 \\
\hline 8 & 0.37 & 0.38 & 0.88 & 0.88 & 1.22 & 0.47 \\
\hline
\end{tabular}

The Route Pointers table $P(i, j)$ is constructed in order to store the values correspondent to the machine that offers the best partial minimum cumulative time (Table 3). The calculation process used to define the manufacturing route begins by ascertaining the position corresponding to the total minimum time of $\mathrm{Z}(1, \mathrm{j})$, for this example Operation 1 and Machine 2. To continue the route the $\mathrm{P}_{\mathrm{ij}}$ element indicates the transfer to the next machine and so on up to the end.

Table 4 - Routes Pointers Table P(i,j)

\begin{tabular}{c|c|c|c|c|c|c}
\hline Transfer & Machine1 & Machine2 & Machine3 & Machine4 & Machine5 & Machine6 \\
\hline $1 \rightarrow 2$ & 1 & 2 & 2 & 2 & 2 & 6 \\
\hline $2 \rightarrow 3$ & 5 & 5 & 5 & 5 & 5 & 5 \\
\hline $3 \rightarrow 4$ & 3 & 2 & 3 & 3 & 3 & 3 \\
\hline $4 \rightarrow 5$ & 1 & 1 & 1 & 1 & 1 & 6 \\
\hline $5 \rightarrow 6$ & 1 & 6 & 6 & 6 & 6 & 6 \\
\hline $6 \rightarrow 7$ & 6 & 6 & 6 & 6 & 6 & 6 \\
\hline $7 \rightarrow 8$ & 1 & 2 & 1 & 1 & 1 & 6 \\
\hline
\end{tabular}

\subsection{STEP 3: Calculate the Schedule}

In small batch manufacturing shops most machines are multipurpose in order to provide the flexibility for this type of production. Another characteristic is the delivery time reliability because most of these shops function as suppliers for other companies in the supply chain. So, the due date is the start point for calculating the schedule.

The machining load is calculated using the following strategy: 
a) Calculate the lead-time for all products required to be manufactured in the period to be scheduled. The calculation for each product is the addition of the optimal times for the tasks, obtained in STEP 2, which comprise product structure (bill of materials). Here the approach is: infinite resource.

b) The critical product, indicated by the optimized criterion and demonstrated by the lead-time, is chosen as the first to be loaded. At this point all the resources required by the process plan for the work period are reserved (made unavailable for other products). Here the finite resource approach is established.

c) The following products are loaded in order of the priority established in the same way to that used in the definition of critical order.

The computer calculation produces a Gantt like chart to illustrate the product structure; Fig. 2 shows an example of two products where the critical one is that assigned as ORDEM 2. The assembly of product order $\mathrm{n}^{\circ} 2$ is treated first. It is scheduled from a set of tasks, each one defined in STEP 2. Task \#5 is the final assembly for 9 items that finish on day 13, the length of the box indicates the time span.

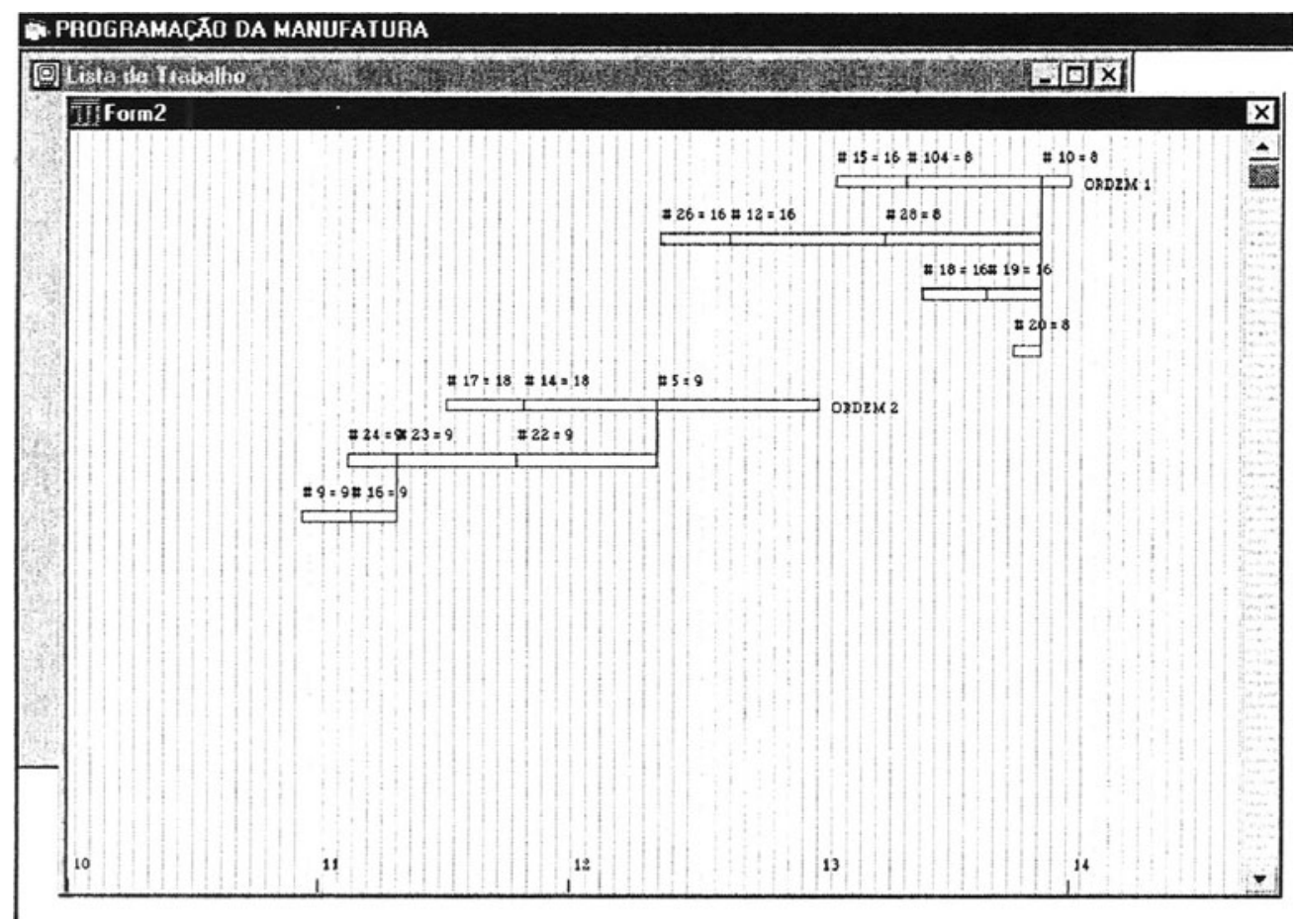

Figure 2 - Product Structure and Lead-Time for Two Orders

At this point the availability of resources, mainly machines, should be considered so, the computer automatically verifies this restriction. When a resource is unavailable STEP 2 is called in and another manufacturing route (the next best option to attend the restriction) is assigned.

The resource chart of Fig. 3 shows the allocation of each machine where the order number/task number in the scheduling (hours) is assigned. For example a code 02009 indicates that machine $n^{\circ} 7$ is loaded during the first hour with task $n^{\circ} 9(009)$ 
of order $n^{\circ} 2(02)$. The manufacturing route of a part can be followed as it progresses through the time (lines) and the various machines are allocated (columns).

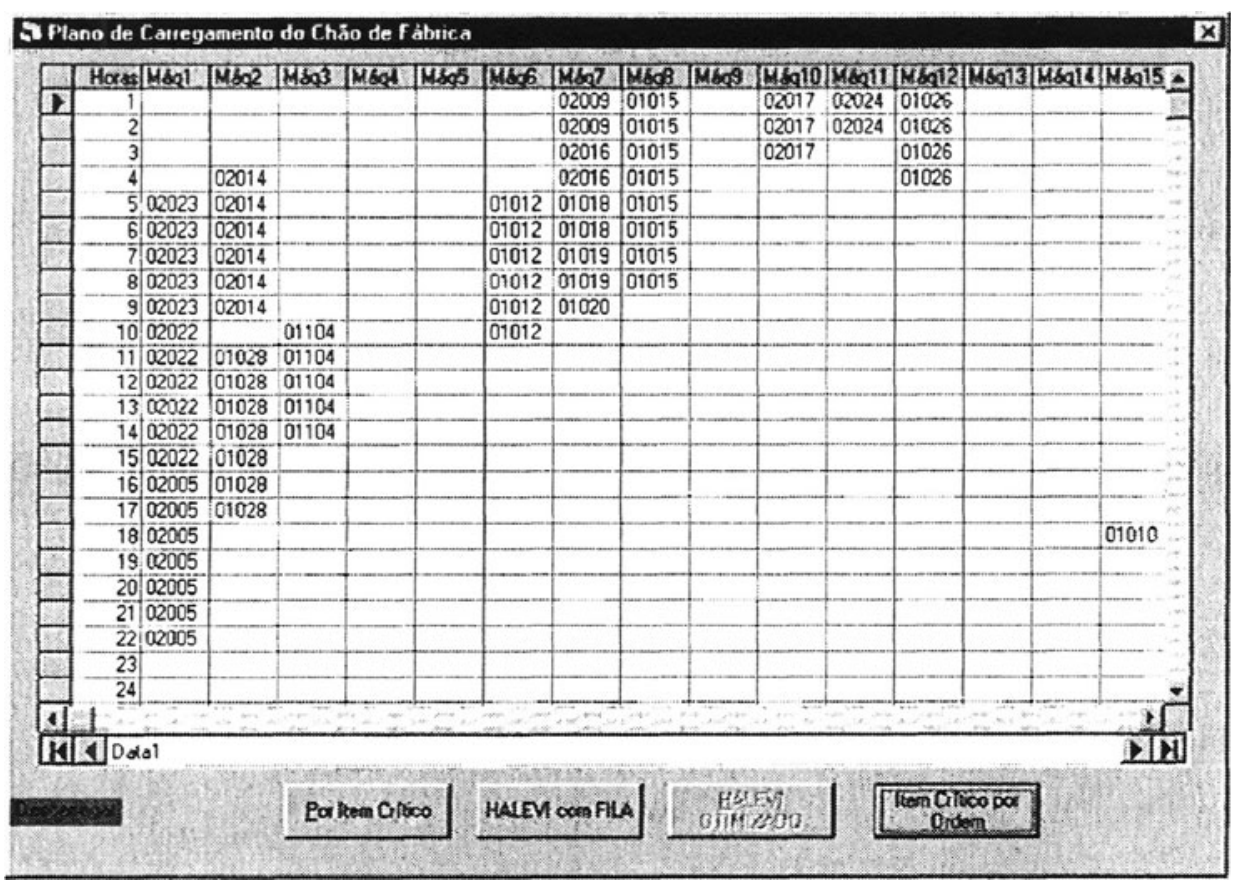

Figure 3 - Machines Scheduling Allocation

\section{CONCLUSIONS}

An improved and focused method of scheduling is the result of this work. Small batch manufacturing with its multiple difficulties and inefficiencies can benefit from decisions on process routes being taken at the last possible moment.

The method begins with some simple work on process planining (STEP 1) and the optimal route at the level of task (STEP 2). The work on scheduling begins with the infinite resource approach considering all products and then choosing the critical product. The finite resource approach begins from the critical product followed by the next critical up to the complete demand, considering all availability of resources. When the calculation is completed the operator can analyze it and, if necessary, make changes and submit again the data to be reprocessed by the system.

This method can be operated in standalone mode or integrated into MRP/ERP systems for pre-process scheduling. The balance between computing data processing and human intervention makes the method a good tool to cope with the extreme flexibility required for the jobbing process in small batch manufacturing. The initial test in manufacturing environments brought very good results. 


\section{ACKNOWLEDGMENTS}

To WEG Máquinas S/A, a Company of the Group WEG Motores - Jaragua do Sul / SC - Brazil where this work was developed in cooperation.

To FINEP and CNPq for the financial support.

\section{REFERENCES}

Bellman R. Dynamic Programming. Princenton: Princenton Univ. Press, 1957.

Halevi, G. The Magic Matrix: the smart scheduler, Computers in Industry, vol. 21, 1993, pp. 245-253.

Halevi, G. Restructuring the manufacturing process, Boca Raton: The St. Lucie Press/APICS Series on resource management, 1999.

Hitomi, K. Manufacturing Systems Engineering. London: Taylor \& Francis Ltd., 1979.

Rantakyro, L. Strategic management in small metal job shops in Sweden and the U. S. Engineering Management Journal, vol. 12. n. 2, 2000, pp. 15-23. 